\title{
Study on Text Reconstruction of English Textbooks in Chinese Senior High School from the Perspective of Language Images
}

\author{
Bin Lu ${ }^{1,2, ~ *, ~ Y u a n y u a n ~} \mathrm{Jin}^{2}$, Shengyan $\mathrm{Shi}^{2}$ \\ ${ }^{1}$ School of Management, Shinawatra University, Bangkok, Thailand \\ ${ }^{2}$ School of Foreign Languages, Luoyang Normal University, Luoyang, China \\ Email address: \\ 2423905702@qq.com (Bin Lu),836403315@qq.com (Yuanyuan Jin),2118903450@qq.com (Shengyan Shi) \\ *Corresponding author
}

\section{To cite this article:}

Bin Lu, Yuanyuan Jin, Shengyan Shi. Study on Text Reconstruction of English Textbooks in Chinese Senior High School from the Perspective of Language Images. Education Journal. Vol. 10, No. 2, 2021, pp. 46-58. doi: 10.11648/j.edu.20211002.12

Received: February 23, 2021; Accepted: March 15, 2021; Published: March 26, 2021

\begin{abstract}
Text reconstruction of textbook is a matter of usual means which can help the classroom guidance of students' learning and critical thinking development. The image configuration of English textbooks in Chinese senior high school becomes one of the new hot topics on logical thinking of English language learning and cognitive symbols now. And the competence of text reconstruction of English teachers is very important knowledge structure for their cross-culture cultivation of cognitive development of Chinese senior students. This study aims to: 1) find out how to stimulate students' new interests in language classroom learning from text reconstruction of English textbooks; 2) investigate both teachers' and students' interests attitudes towards the text reconstruction of English textbooks published by People's Education Press (Abbreviated as PEP); 3) optimize the language logical relationship between language and images in English textbooks in Chinese senior high school, by the mix methods of qualitative and quantitative research based on the theoretical foundation of language image theory and multimodal discourse analysis. A total of 200 teachers from China were investigated in this survey study. The conclusion are: 1) Language image can be found in English textbooks of senior high school, but the logical system of language image has not yet formed; 2) English teachers need improvement the training of text reconstruction to scientifically and accurately understand, extract the logical relationship between images and texts from English textbooks. Suggestions for English teachers are to: 1) broaden the content of different knowledge types of language images related to the text theme; 2) pay attention to cognition cultivation of students' perception on image logical system, so as to have a better understanding of knowledge structure on logical level system, cultural connotation and humanistic thinking expressed in the text; 3) pay attention to improve the classroom competence of text reconstruction which can help the students understand the deeper meaning between language and images from textbooks explanation process.
\end{abstract}

Keywords: English Textbook, Text Reconstruction, Language Image, Image Cognition, Logical Knowledge System

\section{Introduction}

The Ministry of education of the people's Republic of China issued the English curriculum standards for Chinese senior high schools (2017 Edition) on 2018 [1], focusing on "viewing competence" in language skills with "visual literacy" as the key ability which enriches the connotation of core literacy, this guidance help teachers and students to effectively use the images in English textbooks, and also provide a new round of critical thinking of text reconstruction for English textbook in Chinese senior high school. Text reconstruction of textbook is a matter of knowledge structure which can focus the logical relationship between language and image, so as to improve classroom guidance of students' learning and critical thinking development. And the more effective English teachers use in text reconstruction, the better knowledge structure and mind mapping of students will make. The language image of textbook which should be paid attention to in classroom teaching for English teachers, refers to the images which can 
supplement and supply the explanation for text content in English textbook. Since the cultivation of students' English language ability has been changed from focusing only on language knowledge and language ability, to on the value orientation and thinking quality in knowledge structure between different cultures. This is a turning from language centered education to human development centered competence education. From the perspective of cognition competence of senior high school students, students' cognitive thinking mode also should be paid attention to enlightening complementary mode of images and it is conducive to the formation of students' cognitive concept, knowledge system and cross-cultural awareness between different cultures. Based on the view of "Text Reconstruction" proposed by $\mathrm{Pu} \mathrm{Zhu}$ [2], and "Language image theory" proposed by Wittgenstein, this study is to investigate the current situation of English teachers' text reconstruction of English textbooks in Chinese senior high school, and to test the attitude towards contents of language images, such as the language translation or images of Chinese elements, for the future suggestion on compilation reform of English textbooks. And the study also comes from the foundation of earlier discussion between teachers and students on text reconstruction of researcher [3].

\subsection{Research Background}

The key of text reconstruction is a matter of creative use on teaching materials and the embodiment skill of English teachers who will make the secondary development of teaching materials in English textbooks. Before the concept of text reconstruction is proposed, many Chinese experts and scholars have already studied the integration, creative use, and secondary development of textbooks. They have contributed a lot to the domain of English teaching. For example, Hongzhen $\mathrm{Yu}$ discussed in details how to apply the secondary development for teaching materials from the aspects of principles, methods, dimensions, strategies and techniques [4]. Jimei Xia elaborated on how teachers can effectively use teaching materials from four perspectives: teaching materials, learning materials, using materials, and researching materials [5]. Xiaotang Cheng mentioned the selection and adjustment of textbooks in The Analysis and Design of English Textbooks [6]. Teaching focus in English classroom is changed from traditional "teaching materials" to "using teaching materials." It can be seen that text reconstruction is exactly the interpretation and extension of creative using English textbooks and will help the cultivation of students' cross-culture competence.

Foreign experts have not yet clear systematical study of the concept of text reconstruction. But it can be seen from the related researches that they have advocated the creative use of teaching materials in the 1990s. For example, McDonough and Shaw put forward the concept of external factors and internal factors when talking about the choice and adjustment of English textbooks [7]. Cunningsworth believed that teachers had a wide range of choices and adjustments to the textbooks [8]. McGrath (2002) argued that the arrangement of textbook and the student's learning method should be reconsidered [9]. Tomlinson pointed out that there was a lack of theoretical basis for the framework or steps of the textbook development process [10]. Waters (2006) contended that English reading materials were simple and the content was asymmetrical with the students' psychological level, including emotional complexity and cognitive difficulty [11]. In summary, some scholars in foreign countries have involved various aspects of creative use of textbooks. Among them, the adjustment of using teaching materials methods, language selection, classroom situation, teaching process, topic and culture in English textbooks have given some guidance to develop this research.

\subsection{Main Concepts}

A scientific research results need to form a comprehensive understanding on the core concepts. Language image and text reconstruction are key concepts in this study.

\subsubsection{Language Image}

"Language image" theory was proposed by Wittgenstein [12]. Wittgenstein holds that language is not a matter of words or sentences, but a basic proposition. A propositional symbol is a fact, proposition is a real image, so language is the image of the world. According to Wittgenstein's linguistic image theory, proposition is the image of reality, and image is a fact; image represents its meaning; proposition is language. With the development of criticism, language image theory of Wittgenstein changed to use theory [13].

\subsubsection{Text Reconstruction}

$\mathrm{Pu} \mathrm{Zhu,} \mathrm{an} \mathrm{English} \mathrm{teaching} \mathrm{and} \mathrm{research} \mathrm{expert} \mathrm{in}$ Shanghai, China, put forward the concept of text reconstruction in 2010 and pointed out that text reconstruction teaching is also called independent paragraph teaching. It means that in the process of communication, reader should abandon the habit of taking words and sentences as the basis to promote the learning of discourse and context, and put the learned words, phrases, sentence patterns and other scattered knowledge into the appropriate paragraphs for overall understanding and application. In addition, $\mathrm{Pu}$ Zhu advocates the effective learning of sentences with verbs and sentences based on paragraph and context. That is to say, teachers are required to teach words and sentence patterns in specific contexts, stimulate students' interest in learning, mobilize students' pragmatic interest, so as to improve the effectiveness of learning. Weibo Mao defines text reconstruction as a teacher's creative adaptation and integration of the original text of the textbook based on the content of the textbook and the level of students, so as to form a new language learning material with situational and operability context, it can help to improve students' comprehensive language ability [14].

\subsubsection{Textbook Images Characteristics}

Textbook images mainly include color, shape and the overall narrative way of pictures. English textbooks are the core part of English curriculum resources, and textbook images are important learning resources in textbooks. Xun Lu 
said: "the original intention of images or illustrations in books is to decorate books and increase readers' interest, but that power can be more than the images which is lack of words. "Specifically speaking, the functions of textbook images are mainly reflected in the following three aspects: firstly, textbook language images can stimulate new interest in language learning. Interest is the best teacher, inspiring interest is an important task in classroom teaching. Color cartoon pictures in textbooks can stimulate students' interest, meet their visual needs, stimulate their curiosity and improve their learning efficiency. Teachers can use images to create teaching situations, introduce teaching contents, and add corresponding games or interactive links to make the course process more flexible. For example, the design of English image on language expression in accordance with the logical expression of sports science will improve students' cognitive level of learning sports in English language learning and promote their own interest in physical exercise. Secondly, textbook language images can increase the amount of information. The images in textbooks are highly concentrated. Students can acquire rich knowledge through cognitive images and stimulate rich associations of images. Thirdly, images are intuitive. Students can quickly obtain information through cognitive images, and the memory effect of pictures will also assist the memory effect of relevant text content. Therefore, the image research of English textbooks not only provides the language, culture, customs and regional characteristics of different language countries, but also provides students with more specific and intuitive research objects, deepening the cultivation of cross-cultural awareness.

\subsubsection{Text Reconstruction Representation}

The "text reconstruction" of textbooks mainly refers to the appropriate deletion, adjustment and processing of textbook contents by teachers and students in the process of classroom implementation on the basis of the first development of textbooks, and the reasonable selection and development of other teaching textbooks, so as to make them better adapt to the specific education and teaching situation and students' learning requirements. In the process of teaching, teachers are no longer given the right to impart and deduce the content of textbooks, but to teach them creatively. In addition to text mining, it should also pay attention to the logical expression of image language and the auxiliary effect of text reconstruction in the text reconstruction of English textbooks in Chinese senior high school, which is of great significance to the cultivation of students' intercultural communicative thinking ability in senior high school.

\subsection{Research Significance}

In practical significance, the study can stimulate students' interest in learning English language, increase the amount of information on language images, and optimize the complementary structure of English textbooks. The colorful cartoon images in the textbook can stimulate the students' interest, meet the students' visual needs, arouse the students' curiosity and improve their learning efficiency. Teachers can use illustrations to create teaching situations, introduce teaching contents, and add corresponding games or interactive links to make the course process more flexible. And students can acquire rich knowledge and stimulate their rich association of images through cognitive images. At the same time, images are intuitive, students can quickly obtain information through cognitive images, and the memory effect of images can also assist the memory effect of relevant text content. Through the study of language images in English textbooks in Chinese senior high school, it is instructive to pay attention to the representation of image language, image color, image modeling, image narrative and image logical representation in the future textbooks. It is also helpful for teachers to reconstruct texts and further optimize teaching materials.

\section{Research Design}

\subsection{Research Problems}

This study mainly explores the following three research problems:

1) What's the characteristics of language images in the PEP version of English textbooks of senior high school and the education value of text reconstruction?

2) What are English teachers' attitude towards text reconstruction adopted in the process of English classroom teaching?

3) What's the contents' attitude towards language images representation of English textbooks of senior high school and suggestions for text reconstruction?

\subsection{Research Objectives}

The research objectives are following:

1) To find out how to stimulate students' new interests in text reconstruction of language teaching, characteristics of language images in the PEP version of English textbooks of senior high school and the education value of text reconstruction.

2) To investigate English teachers' attitude towards text reconstruction adopted in the process of English classroom teaching.

3) To optimize the contents' attitude towards language images representation of English textbooks of senior high school and suggestions for text reconstruction.

\subsection{Research Methods}

This study focuses on characteristics of language image and teachers' attitudes towards language image and text reconstruction of English textbooks which is published by PEP in Chinese senior high school. The research designed as a mixed research methods of qualitative and quantitative method. It uses content analysis to collect qualitative data from English textbooks of senior high school and English textbooks published by PEP and uses survey questionnaire of quantitative method to collect data from the English teachers in Henan Province, China.

While making the deep understanding of text 
reconstruction, this study should use text analysis method which aims to make statistic analysis of images in English textbooks and analyze the logical relationship between language in text and images to find a better way of achieving text reconstruction. The process of studying the knowledge structure of graphic logical relationship is divided into three steps. The first step is to make macro statistic analysis of the images presented in English textbooks, images in English textbooks are sort out and classified, such as on Chinese elements, foreign elements, society, nature, science and technology and so on. The second step is to collect data analysis the above elements in the teaching materials, in order to find the distribution of images in the text. The third step is to study the auxiliary role of images, supply the attitude towards the way of text reconstruction among English teachers, and improve the development and utilization of the complementary of pictures and texts in teaching materials in a wider range.

In the process of researching the teachers' attitude toward of different images and pictures of English textbook when they are involved in text reconstruction, the questionnaire is carried out to know whether English teachers' attitude on different contents of images of English textbooks, especially the attitude of teachers are changed when they begin to pay attention to the application of text reconstruction based on the language image theory. And in quantitative research, English teachers' attitude towards different culture elements on images in English textbooks will be discussed from the following five aspects: teachers' attitude towards the importance of image text construction; teachers' general attitudes on the contents; content forms; usage of images; and students' attitudes towards textbook images from the teacher's perspective in English textbooks of Chinese senior high school.

\subsection{Research Hypothesis}

Eight hypotheses have been set for study purpose. All these are as following:

$\mathrm{H} 1$ : There are systematic language images in English textbooks of Chinese senior high school.

$\mathrm{H} 2$ : There is less positive correlation between the teacher with different gender and the attention of language image and text reconstruction in English textbooks.

H3: There is less positive correlation between the teacher who have ages and the attention of language image and text reconstruction in English textbooks.

H4: There is less positive correlation between the teacher with professional ranking and the attention of language image and text reconstruction in English textbooks.

H5: There is less positive correlation between the teacher with the different cities and the attention of language image and text reconstruction in English textbooks.

H6: There is less positive correlation between the teacher who teaches different grade and the attention of language image and text reconstruction in English textbooks.

H7: There is less positive correlation between the teacher who have different length of teaching and the attention of language image and text reconstruction in English textbooks.
H8: There is less positive correlation between the versions of English teachers using and the attention of language image and text reconstruction in English textbooks

\subsection{Data Collecting Method}

This study analyzes the characteristics of language image in English textbooks of Chinese senior high school, and investigates the English teachers' attitude towards language image and text reconstruction in their classroom teaching. Taking language image distributed by "life", "nature", "humanities", "technology" and "others" groups to be statistic analysis. 200 questionnaires towards language image and text reconstruction in English textbooks of senior high school for English teachers from different cities of China will be discussed. Based on the content of language image in English textbooks of senior high school and the attitude of English teachers to language image and text reconstruction, this study puts forward some suggestions on how to further improve text reconstruction of language image in English textbooks of senior high school.

The method to collect data are as following:

To define the concepts of language image and text reconstruction in English textbooks of senior high school;

To design the questionnaire survey of teachers on data collection; and carry out the quantitative research of English teachers on attitude towards language image and text reconstruction in English textbooks of senior high school;

To collect the data and data analysis;

The design of teachers' questionnaire includes 2 parts: the first is basic information survey of the participants, including gender, age group, professional ranking, school, grade, and length of teaching; the second is 16 single choices designed by using Likert scale (Level 5), and the principle of scoring including "1"refers to "strongly disagree", "2" refers to "disagree", "3" refers to "not sure", "4" refers to "agree", "5" refers to "strongly agree". In the scale of questionnaire, it includes 5 Item s following:

Item 1: English teachers' cognition towards the importance of paying attention to logical relationship between image and text in English textbooks.

Item 2: English teachers' cognition towards the relationship between image and text in English textbooks.

Item 3: English teachers' cognition towards the the distribution of the relationship between images and texts in English textbooks.

Item 4: English teachers' cognition towards the dealing of the relationship between images and texts in English classroom teaching.

Item 5: English teachers' attitude towards the scientific and reasonable relationship between images and texts of students preference.

\section{Data Analysis and Discussion}

In this part, the characteristics and functions of images in textbooks will be investigated on the foundation of data analysis. The total number of images in the five volumes of 
the English textbook published by PEP was counted and sorted in two cognitive stages. The first is the visual cognition stage, which is to classify and describe the images of English textbooks from the statistic data level. The second is the sense cognition stage, which makes a variety of comparative analysis on the images of this set of textbooks [15]. Therefore, this study aims to: 1) find out how to stimulate students' new interests in language learning from text reconstruction of
English textbooks; 2) investigate both teachers and students interests attitudes towards text reconstruction of English textbooks in Chinese senior high school; 3) optimize the language logical relationship between language and images in English textbooks by the mix methods of qualitative and quantitative research based on the theoretical foundation of language image theory and multimodal discourse analysis. The specific analysis is shown in the following table:

Table 1. Percent of Image Language.

\begin{tabular}{|c|c|c|c|c|}
\hline & Class Period & Total Number & Subject Related & Correlation Ratio \\
\hline \multirow{5}{*}{ Volume 1} & Unit 1 Friendship & 8 & 6 & $75.00 \%$ \\
\hline & Unit 2 English around the world & 16 & 12 & $75.00 \%$ \\
\hline & Unit 3 Travel journal & 9 & 7 & $77.78 \%$ \\
\hline & Unit 4 Earthquakes & 7 & 7 & $100.00 \%$ \\
\hline & Unit 5 Nelson Mandela-a modern hero & 15 & 15 & $100.00 \%$ \\
\hline \multirow{4}{*}{ Volume 2} & Unit 1 Cultural relics & 23 & 22 & $95.65 \%$ \\
\hline & Unit 2 The Olympic Games & 10 & 8 & $80.00 \%$ \\
\hline & Unit 4 Wildlife protection & 11 & 10 & $90.91 \%$ \\
\hline & Unit 5 Music & 18 & 14 & $77.78 \%$ \\
\hline \multirow{5}{*}{ Volume 3} & Unit 1 Festivals around the world & 20 & 20 & $100.00 \%$ \\
\hline & Unit 2 Healthy eating & 7 & 3 & $42.86 \%$ \\
\hline & Unit 3 The Million Pound Bank Note & 11 & 3 & $27.27 \%$ \\
\hline & Unit 4 Astronomy: the science of the stars & 9 & 9 & $100.00 \%$ \\
\hline & Unit 5 Canada-"The True North" & 12 & 12 & $100.00 \%$ \\
\hline \multirow{4}{*}{ Volume 4} & Unit 1 Women of achievement & 12 & 12 & $100.00 \%$ \\
\hline & Unit 3 A taste of English humour & 5 & 4 & $80.00 \%$ \\
\hline & Unit 4 Body language & 9 & 9 & $100.00 \%$ \\
\hline & Unit 5 Theme parks & 17 & 15 & $88.24 \%$ \\
\hline \multirow{5}{*}{ Volume 5} & Unit 1 Great scientists & 13 & 12 & $92.31 \%$ \\
\hline & Unit 2 The Unit ed Kingdom & 12 & 12 & $100.00 \%$ \\
\hline & Unit 3 Life in the future & 7 & 7 & $100.00 \%$ \\
\hline & Unit 4 Making the news & 4 & 3 & $75.00 \%$ \\
\hline & Unit 5 First aid & 13 & 13 & $100.00 \%$ \\
\hline
\end{tabular}

\subsection{The Classification of Language Images in English Textbooks}

In the process of image language induction, there are many images that can match and express the theme content, but the content of these images is lack of system and logical connotation. In the volume 1, unit 1 "earthquakes" in English textbooks in Chinese senior high school, almost all the contents are the description of the earthquake and the comparison between the before and the after statement of the earthquake, lack of humanistic care, rescue activities, life education, image guidance and education content; for the relief scene, there is only one Tangshan earthquake rescue image language presentation. In fact, Wenchuan earthquake rescue scene can be added, and supply the materials of the content or personal experience is more likely to deepen students' understanding of the text and pay more attention to the self rescue about the earthquake disaster in China. It is more likely to have emotional resonance of reverence for life, stimulate the study potential of solving the natural disaster for all human being in the world. In addition, there is a lack of description of earthquake science history, development and its representatives technology. For example, the seismograph invented by Heng Zhang, a famous ancient
Chinese scientist, is the first step in ancient earthquake exploration and early warning in Chinese history. It will be helpful to add the image logic of science development of Chinese earthquake and technology history vertically and horizontally in textbooks.

\subsection{The Content Distribution of Language Images in English Textbooks}

The language image in this set of textbooks is more appropriate, but the image logic is still scattered and lack of systematic. There are more "life" images and less "science and technology" images at the basic level, which indicates that in English textbooks, the relevant contents of international scientific and technological development are insufficient and can not keep pace with the society development; at the same time, there are more "humanistic" images and less "natural" images, which indicates that in English textbooks, there are many images of "humanity" and "nature". These two element "life" and "humanistic" are very important to construct the knowledge structure of students, but the textbook should pay attention to the balance of education materials for the universal view on human and nature. The importance of images should be paid attention to as well as the importance of language learning. 
Table 2. Content Distribution of Image Language.

\begin{tabular}{|c|c|c|c|c|c|c|}
\hline & Class period & Life & Nature & Humanity & Science & Others \\
\hline \multirow{5}{*}{ Volume 1} & Unit 1 Friendship & 6 & 1 & 1 & 1 & 1 \\
\hline & Unit 2 English around the world & 12 & I & 3 & I & 1 \\
\hline & Unit 3 Travel journal & / & 2 & 7 & / & 1 \\
\hline & Unit 4 Earthquakes & 1 & 4 & 2 & / & l \\
\hline & Unit 5 Nelson Mandela-a modern hero & / & / & 15 & / & l \\
\hline \multirow{5}{*}{ Volume 2} & Unit 1 Cultural relics & l & 1 & 22 & l & 1 \\
\hline & Unit 2 The Olympic Games & 2 & I & 8 & I & I \\
\hline & Unit 3 Computers & / & / & / & 11 & / \\
\hline & Unit 4 Wildlife protection & 1 & 10 & / & / & l \\
\hline & Unit 5 Music & 8 & / & 10 & / & 1 \\
\hline \multirow{5}{*}{ Volume 3} & Unit 1 Festivals around the world & l & I & 19 & / & 1 \\
\hline & Unit 2 Healthy eating & 7 & I & / & / & 1 \\
\hline & Unit 3 The Million Pound Bank Note & / & l & 11 & / & l \\
\hline & Unit 4 Astronomy: the science of the stars & / & / & 1 & 8 & I \\
\hline & Unit 5 Canada-"The True North" & l & 5 & 5 & 1 & 1 \\
\hline \multirow{5}{*}{ Volume 4} & Unit 1 Women of achievement & / & 1 & 11 & l & l \\
\hline & Unit 2 Working the land & 5 & / & 3 & / & 1 \\
\hline & Unit 3 A taste of English humour & 2 & / & 3 & / & I \\
\hline & Unit 4 Body language & 8 & 1 & / & / & 1 \\
\hline & Unit 5 Theme parks & / & / & / & / & 17 \\
\hline \multirow{5}{*}{ Volume 5} & Unit 1 Great scientists & 1 & I & 9 & 3 & I \\
\hline & Unit 2 The Unit ed Kingdom & / & l & 9 & / & 3 \\
\hline & Unit 3 Life in the future & / & I & l & 7 & I \\
\hline & Unit 4 Making the news & 3 & / & / & / & 1 \\
\hline & Unit 5 First aid & 13 & 1 & 1 & 1 & / \\
\hline
\end{tabular}

The images of English culture in foreign countries are more involved, and more logical expression lies in the primary communication level among people greetings, rather than rising to the advanced level of harmonious coexistence between man and nature. It will be helpful to form an image logical system which combining the cognitive and psychological characteristics of students in the process of cultural expression between foreign counties and China, therefore, the richness of image content needs to be improved, language images can be reconstruct in English textbooks from the cognition perspective. In order to find out the related representation characteristics and distribution proportion, it should broaden the content of different types of language images related to the theme, pay attention to the cultivation of students' sensory awareness, so as to have a better understanding of the degree of language learning, logical system, cultural connotation and humanistic thought expressed in the textbooks. From this point, this study accept the hypothesis 1 "There are uneven language images in English textbooks of senior high school".

\subsection{Reliability Statistics and Validity Analysis of Questionnaire}

The following data collection is based on the English teachers who participate practical teaching and real questionnaire survey. This study uses SPSS 26.0 for data analysis. Through the analysis, it analyzes the presentation characteristics of images, the logical relationship between images and texts, and the cognition of teachers and students on the distribution of the relationship between pictures and texts in the textbook.
Table 3. Reliability Analysis of Teachers' Questionnaire.

\begin{tabular}{ll}
\hline Reliability Statistics & \\
\hline Cronbach's Alpha & N of Item s \\
\hline .934 & 16 \\
\hline
\end{tabular}

Reliability analysis is used to study whether the data is true and reliable, that is, whether the research sample has answered the question (questionnaire P6). The commonly used method is Cronbach's alpha, which is generally greater than 0.7 . It can be seen from table 3 that Cronbach's alpha is 0.934 , greater than 0.7 , so the reliability of the scale is high.

Table 4. Validity Analysis of Teachers' Questionnaire.

\begin{tabular}{lll}
\hline \multicolumn{3}{l}{ KMO and Bartlett's Test } \\
\hline \multicolumn{3}{l}{ Kaiser-Meyer-Olkin Measure of Sampling Adequacy. } \\
\hline \multirow{3}{*}{ Bartlett's Test of Sphericity } & Approx. Chi-Square & $\mathbf{. 9 0 1}$ \\
& df & 1239.368 \\
& Sig. & .000 \\
\hline
\end{tabular}

Validity analysis is used to determine whether the research questions effectively express the conceptual information of research variables or dimensions, that is, whether the design of research questions is reasonable. The Kaiser-Meyer-Olkin Measure of Sampling Adequacy. is 0.901, greater than 0.7, so the scale has high validity. In order to have a better understanding on the situation of English teachers who use English textbooks to make text reconstruction in Chinese senior high school, this study distributed questionnaires to teachers online in different cities and schools. The questionnaires were anonymous. 
Table 5. Basic Information of English Teachers.

\begin{tabular}{|c|c|c|c|}
\hline Classification & Frequency & & Percent \\
\hline \multirow{2}{*}{ Gender } & Male & 45 & $22.5 \%$ \\
\hline & Female & 155 & $77.5 \%$ \\
\hline \multirow{4}{*}{ Age } & $21-30$ & 45 & $22.6 \%$ \\
\hline & $31-40$ & 93 & $46.7 \%$ \\
\hline & $41-50$ & 40 & $20.1 \%$ \\
\hline & $51-60$ & 21 & $10.6 \%$ \\
\hline \multirow{4}{*}{ Professional Title } & No & 25 & $12.5 \%$ \\
\hline & Junior & 68 & $34.0 \%$ \\
\hline & Intermediate & 75 & $37.5 \%$ \\
\hline & Senior & 32 & $16.0 \%$ \\
\hline \multirow{3}{*}{ School } & Henan & 148 & $74.0 \%$ \\
\hline & Others & 52 & $26.0 \%$ \\
\hline & Senior 1 & 66 & $33.0 \%$ \\
\hline \multirow{3}{*}{ Grade } & Senior 2 & 60 & $30.0 \%$ \\
\hline & Senior 3 & 54 & $27.0 \%$ \\
\hline & Compulsory & 20 & $10.0 \%$ \\
\hline \multirow{4}{*}{ Versions } & PEP & 97 & $48.5 \%$ \\
\hline & BNUPH & 76 & $38.0 \%$ \\
\hline & FLTRP & 22 & $11.0 \%$ \\
\hline & Others & 5 & $2.5 \%$ \\
\hline
\end{tabular}

\subsection{Correlation Analysis of Basic Information and Attention (Total Score)}

According to the survey data, $77.5 \%$ of the female teachers fill in the form, and $74.0 \%$ of the teachers come from Henan. The age of teachers is mainly between 31 and 40 years old, indicating that most of them are young and middle-aged teachers. Young and middle-aged teachers usually have a wide range of knowledge, strong plasticity, certain affinity, and strong sensitivity and attention to teaching, they are more likely to complete the text reconstruction in diversity methods. From the data collection, the most part of English textbooks are from PEP, accounting for $48.5 \%$. Teachers have certain teaching experience and are distributed in three different grades, among which $53.5 \%$ have middle and senior professional rankings. Therefore, teachers are serious when filling in the questionnaire, and the survey results are rigorous.

It can be seen from the figure 1 that the total scores of 200 senior high school English teachers are normal distribution roughly, and Pearson correlation analysis can be used to analyze the correlation.

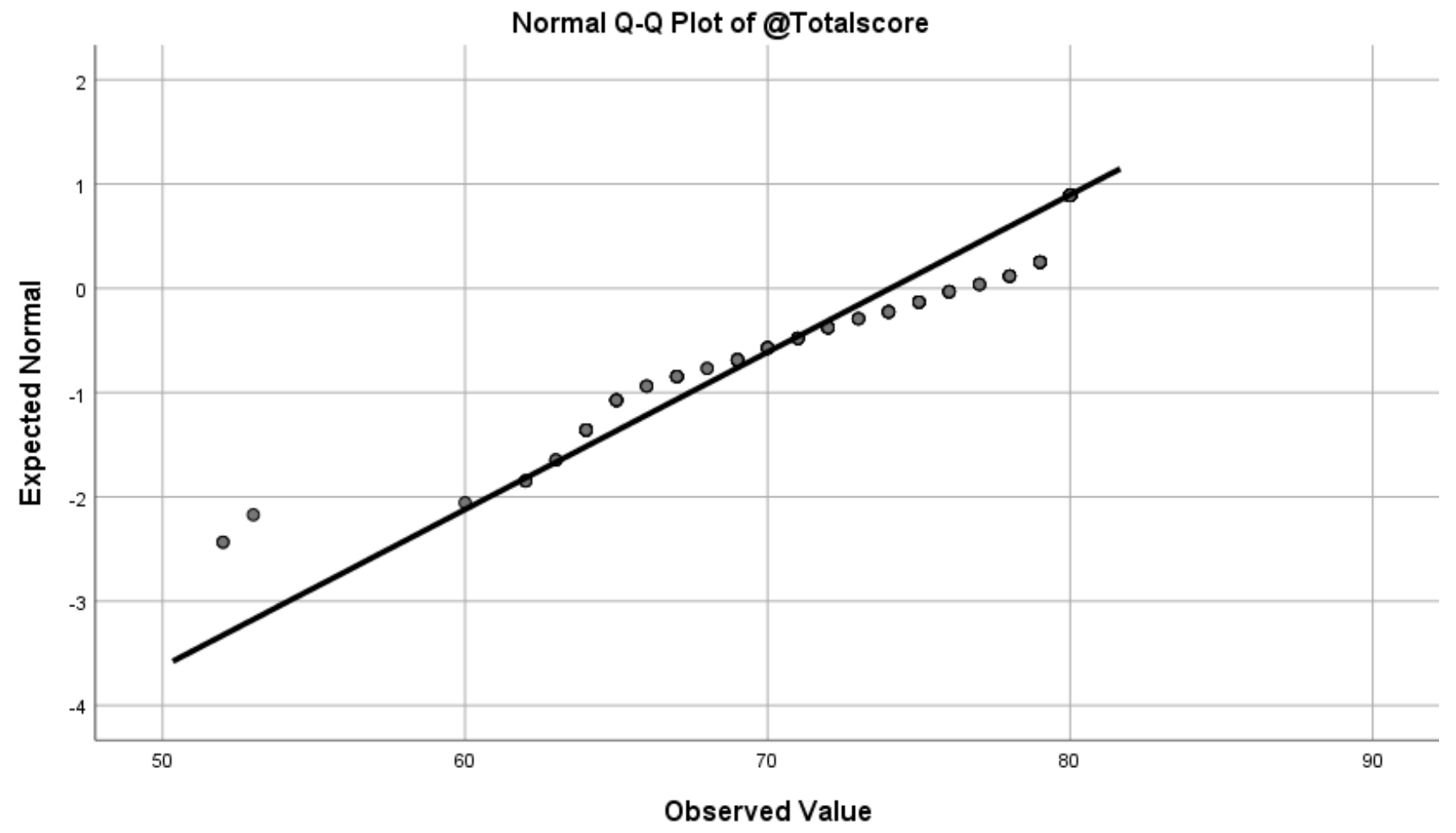

Figure 1. Normal Q-Q Plot of Total Score in English Questionnaire.

Table 6. Correlation Analysis between Total Score and Gender.

\begin{tabular}{llll}
\hline \multicolumn{2}{l}{ Correlations } & & \\
\hline & & Gender & Total score \\
\hline \multirow{3}{*}{ Gender } & Pearson Correlation & 1 & .115 \\
& Sig. (2-tailed) & & .104 \\
& $\mathrm{~N}$ & 200 & 200 \\
\multirow{2}{*}{ Total } & Pearson Correlation & .115 & 1 \\
score & Sig. (2-tailed) & .104 & \\
& $\mathrm{~N}$ & 200 & 200 \\
\hline
\end{tabular}

As can be seen from the table 6, Pearson correlation coefficient is $0.115,0.115<0.3$, sig. is $0.104,0.104>0.05$, so it can be judged that there is no significant positive correlation between gender and total score. So, this study accept the hypothesis 2 "There is less positive correlation between the teacher with different gender and the attention of language image and text reconstruction in English textbooks". 
Table 7. Correlation Analysis between Total Score and Age.

\begin{tabular}{llll}
\hline Correlations & & & \\
\hline & & Age & Total score \\
\hline \multirow{4}{*}{ Age } & Pearson Correlation & 1 & -.052 \\
& Sig. (2-tailed) & & .465 \\
\multirow{4}{*}{ Total score } & $\mathrm{N}$ & 199 & 199 \\
& Pearson Correlation & -.052 & 1 \\
& Sig. (2-tailed) & .465 & \\
& $\mathrm{~N}$ & 199 & 200 \\
\hline
\end{tabular}

As can be seen from the table 7, Pearson correlation coefficient is $-0.052,-0.052<0.3$, which can be judged as uncorrelated; sig. is $0.465,0.465>0.05$, which is not significant positive correlation between age and total score. So, this study accept the hypothesis 3 "There is less positive correlation between the teacher who have ages and the attention of language image and text reconstruction in English textbooks."

Table 8. Correlation Analysis between Total Score and Professional Title.

\begin{tabular}{|c|c|c|c|}
\hline \multicolumn{4}{|l|}{ Correlations } \\
\hline & & Professional Title & Total score \\
\hline \multirow{3}{*}{ Professional Title } & Pearson Correlation & 1 & -.089 \\
\hline & Sig. (2-tailed) & & .212 \\
\hline & $\mathrm{N}$ & 200 & 200 \\
\hline \multirow{3}{*}{ Total score } & Pearson Correlation & -.089 & 1 \\
\hline & Sig. (2-tailed) & .212 & \\
\hline & $\mathrm{N}$ & 200 & 200 \\
\hline
\end{tabular}

As can be seen from the table 8, Pearson correlation coefficient is $-0.089,-0.089<0.3$, which can be judged as uncorrelated; sig. is $0.212,0.212>0.05$, which is not significant positive correlation between the title and the total score. So, this study accept the hypothesis 4 "There is less positive correlation between the teacher with professional ranking and the attention of language image and text reconstruction in English textbooks".

Table 9. Correlation Analysis between Total score and School.

\begin{tabular}{llll}
\hline Correlations & & & Total score \\
\hline & & School & .022 \\
\multirow{3}{*}{ School } & Pearson Correlation & 1 & .755 \\
& Sig. (2-tailed) & 200 & 200 \\
\multirow{3}{*}{ Total score } & N & .022 & 1 \\
& Pearson Correlation & .755 & 200 \\
\hline
\end{tabular}

As can be seen from the table 9, Pearson correlation coefficient is $0.022,0.022<0.3$, it can be judged that there is no correlation; sig. is $0.755,0.755>0.05$, so it is not significantly positive correlation between school and total score. So, this study accept the hypothesis 5 "There is less positive correlation between the teacher with the different cities and the attention of language image and text reconstruction in English textbooks".

Table 10. Correlation Analysis between Total Score and Grade.

\begin{tabular}{llll}
\hline Correlations & & Grade & Total score \\
\hline \multirow{3}{*}{ Grade } & Pearson Correlation & 1 & -.085 \\
& Sig. (2-tailed) & & .230 \\
\multirow{2}{*}{ Total score } & $\mathrm{N}$ & 200 & 200 \\
& Pearson Correlation & -.085 & 1 \\
\hline
\end{tabular}

As can be seen from the table 10, Pearson correlation coefficient is $-0.085,-0.085<0.3$, which can be judged as uncorrelated; sig. is $0.230,0.230>0.05$, so it is not significantly positive correlation between grade and total score. So, this study accept the hypothesis 6 "There is less positive correlation between the teacher who teaches different grade and the attention of language image and text reconstruction in English textbooks".

Table 11. Correlation Analysis between Total Score and Length of Teaching.

\begin{tabular}{llll}
\hline Correlations & & & \\
\hline & & Length of teaching & Total score \\
\hline \multirow{3}{*}{ Length of teaching } & Pearson Correlation & 1 & -.049 \\
& Sig. (2-tailed) & & .487 \\
\multirow{3}{*}{ Total score } & $\mathrm{N}$ & 200 & 200 \\
& Pearson Correlation & -.049 & 1 \\
& Sig. (2-tailed) & .487 & 200 \\
\hline
\end{tabular}


As can be seen from the table 11, Pearson correlation coefficient is $-0.049,-0.049<0.3$, which can be judged as uncorrelated; sig. is $0.487,0.487>0.05$, so it is not significantly positive correlation between the length of teaching and the total score. So, this study accept the hypothesis 7 "There is less positive correlation between the teacher who have different length of teaching and the attention of language image and text reconstruction in English textbooks".

Table 12. Correlation Analysis between Total Score and Versions.

\begin{tabular}{llll}
\hline Correlations & & & Total score \\
\hline & & Versions & .083 \\
Versions & Pearson Correlation & 1 & .245 \\
& Sig. (2-tailed) & & 200 \\
\multirow{3}{*}{ Total score } & $\mathrm{N}$ & 200 & 1 \\
& Pearson Correlation & .083 & 200 \\
\hline
\end{tabular}

As can be seen from the table 12, Pearson correlation coefficient is $0.083,0.083$ is less than 0.3 , which can be judged as uncorrelated; sig. is $0.245,0.245>0.05$, so it is not significantly positive correlation between the versions of teachers using and the total score. So, this study accept the hypothesis 8 "There is less positive correlation between the versions of English teachers using and the attention of language image and text reconstruction in English textbooks".

Table 13. Correlation Analysis between Item s.

\begin{tabular}{|c|c|c|c|c|c|c|}
\hline \multicolumn{7}{|c|}{ Correlations } \\
\hline & & Item 1 & Item 2 & Item 3 & Item 4 & Item 5 \\
\hline \multirow[t]{2}{*}{ Item 1} & $\begin{array}{l}\text { Pearson Correlation } \\
\text { Sig. (2-tailed) }\end{array}$ & 1 & & & & \\
\hline & $\mathrm{N}$ & 200 & & & & \\
\hline \multirow{3}{*}{ Item 2} & Pearson Correlation & $.699^{* *}$ & 1 & & & \\
\hline & Sig. (2-tailed) & .000 & & & & \\
\hline & $\mathrm{N}$ & 200 & 200 & & & \\
\hline \multirow[t]{2}{*}{ Item 3} & Sig. (2-tailed) & .000 & .000 & & & \\
\hline & $\mathrm{N}$ & 200 & 200 & 200 & & \\
\hline \multirow{3}{*}{ Item 4} & Pearson Correlation & $.516^{* *}$ & $.665^{* *}$ & $.760^{* *}$ & 1 & \\
\hline & Sig. (2-tailed) & .000 & .000 & .000 & & \\
\hline & $\mathrm{N}$ & 200 & 200 & 200 & 200 & \\
\hline \multirow[b]{2}{*}{ Item 5} & Pearson Correlation & $.571^{* *}$ & $.680^{* *}$ & $.634^{* *}$ & $.649^{* *}$ & 1 \\
\hline & Sig. (2-tailed) & .000 & .000 & .000 & .000 & \\
\hline
\end{tabular}

**. Correlation is significant at the 0.01 level (2-tailed).

Part 1, Part 2, Part 3, Part 4 and Part 5 in the table 13 respectively refer to the importance of reasonable graphic relationship, teachers' cognition of graphic relationship in textbooks, teachers' cognition of distribution of graphic relationship in specific contents of textbooks, teachers' handling of graphic relationship in teaching and students' attitude towards scientific and reasonable graphic relationship from the perspective of teachers. It can be seen from the table that the correlation coefficient values of each of the five factors are greater than 0.3 , indicating that they are related to each other; sig. is 0.000 , indicating that $\mathrm{P}<$
0.05 , there is a linear correlation.

The next part of the questionnaire is a descriptive analysis of English teachers' attitudes towards language images and text reconstruction in English textbooks of senior high school.

\subsection{Descriptive Analysis of English Teachers' Questionnaire}

Item 1: English teachers' cognition towards the importance of paying attention to logical relationship between image and text in English textbooks.

Table 14. Descriptive Analysis of Q8-Q10 in English Teachers' Questionnaire.

\begin{tabular}{|c|c|c|c|c|c|c|c|}
\hline \multicolumn{8}{|c|}{ Q8-Q10 } \\
\hline & Mean & Std. Deviation & Very disagree & Disagree & Not sure & Agree & Strongly agree \\
\hline Q8 & 4.72 & .505 & $0(0.0 \%)$ & $0(0.0 \%)$ & $5(2.5 \%)$ & $47(23.5 \%)$ & $148 \quad(74.0 \%)$ \\
\hline Q9 & 4.64 & .551 & $0(0.0 \%)$ & $0(0.0 \%)$ & $7(3.5 \%)$ & $59(29.5 \%)$ & $(67.0 \%)$ \\
\hline Q10 & 4.67 & .568 & $0(0.0 \%)$ & $1(0.5 \%)$ & $7(3.5 \%)$ & $49(24.5 \%)$ & $(71.5 \%)$ \\
\hline
\end{tabular}

Table 14 shows the attitude of English teachers from senior high school towards the importance of reasonable relationship between images and texts. For question 8,148 (74.0\%) agreed with it very much; 47 (23.5\%) agreed with it; 
the mean value was 4.72 ; the standard deviation was 0.505 . And question 9, there were $134(67.0 \%)$ who agreed with it very much and $59(29.5 \%)$ who agreed with it. The mean value was 4.64 and the standard deviation was 0.551 . As for question 10, 143 (71.5\%) agreed very much, and 49 (24.5\%) agreed. The mean value was 4.67 , and the standard deviation was 0.568 . The average value of the above three questions is close to 5, which indicates that teachers pay more attention to the importance of reasonable graphic relationship between the images and texts; the standard deviation is relatively close to 0 , which indicates that the degree of dispersion is low, and teachers' attitude on this issue is more concentrated.

Item 2: English teachers' cognition towards the relationship between image and text in English textbooks

Table 15. Descriptive Analysis of Q12-Q14 in English Teachers' Questionnaire.

\begin{tabular}{|c|c|c|c|c|c|c|c|}
\hline \multicolumn{8}{|c|}{ Q12-Q14 } \\
\hline & Mean & Std. Deviation & Very disagree & Disagree & Not sure & Agree & Strongly agree \\
\hline Q12 & 4.73 & .480 & $0(0.0 \%)$ & $0(0.0 \%)$ & $3(1.5 \%)$ & $49(24.5 \%)$ & $148 \quad(74.0 \%)$ \\
\hline Q13 & 4.68 & .538 & $0(0.0 \%)$ & $1(0.5 \%)$ & $4(2.0 \%)$ & $53(26.5 \%)$ & $(71.0 \%)$ \\
\hline Q14 & 4.44 & .787 & $1(0.5 \%)$ & $1(0.5 \%)$ & $13(6.5 \%)$ & $64(32.0 \%)$ & $(58.0 \%)$ \\
\hline
\end{tabular}

Table 15 shows teachers' cognition of the relationship between images and texts in English textbooks. As for question 12,148 people $(74.0 \%)$ agreed very much, and 49 people $(24.5 \%)$ agreed. The mean value was 4.73 , and the standard deviation was 0.480 . For question 13,142 people $(71.0 \%)$ agreed with it very much; 53 people $(26.5 \%)$ agreed with it; the mean value was 4.68 ; the standard deviation was 0.538 . As for question 14,116 people $(58.0 \%)$ agreed very much, 64 people $(32 \%)$ agreed, the mean value was 4.44 , and the standard deviation was 0.787 . The average value of the above three questions is close to 5 , which indicates that teachers have a certain cognition of the relationship between images and texts in English textbooks; the standard deviation is relatively close to 0 , which indicates that the degree of dispersion is low, and teachers' cognition on this issue is relatively concentrated.

Item 3: English teachers' cognition towards the the distribution of the relationship between images and texts in English textbooks

Table 16. Descriptive Analysis of Q15-Q18 in English Teachers' Questionnaire.

\begin{tabular}{llllllll}
\hline Q15-Q18 & & & & & & \\
\hline & Mean & Std. Deviation & Very disagree & Disagree & Not sure & Agree & Strongly agree \\
\hline Q15 & 4.72 & .482 & $0(0.0 \%)$ & $0(0.0 \%)$ & $3(1.5 \%)$ & $50(25.0 \%)$ & 147 \\
Q16 & 4.70 & .519 & $0(0.0 \%)$ & $0(0.0 \%)$ & $6(3.0 \%)$ & $47(23.5 \%)$ & $147(73.5 \%)$ \\
Q17 & 4.65 & .557 & $0(0.0 \%)$ & $0(0.0 \%)$ & $8(4.0 \%)$ & $55(27.5 \%)$ & $137 \quad(68.5 \%)$ \\
Q18 & 4.38 & .824 & $1(0.5 \%)$ & $7(3.5 \%)$ & $17(8.5 \%)$ & $65(32.5 \%)$ & $110(55.0 \%)$ \\
\hline
\end{tabular}

Table 16 shows the teacher's cognition of the relationship between text and text in the textbook. As for question 15, 147 people (73.5\%) agreed very much; 50 people $(25 \%)$ agreed; the mean value was 4.72 ; the standard deviation was 0.482 . As for question 16,147 people $(73.5 \%)$ agreed very much, and 47 people $(23.5 \%)$ agreed. The mean value was 4.70 , and the standard deviation was 0.519 . For question 17 , there are 137 people who hold extraordinary agreement, accounting for $68.5 \%$; there are 55 people who hold agreement, accounting for $27.5 \%$; the average is 4.65 ; the standard deviation is 0.557 . For question 18 , there are 110 people who hold extraordinary agreement, accounting for $55.0 \% ; 65$ people hold agreement, accounting for $24.5 \%$; the average is 4.38; the standard deviation is 0.824 . The average value of the above four questions is close to 5 , which indicates that teachers have a certain cognition of the relationship between images and texts in the specific content of English textbook; the standard deviation is relatively close to 0 , which indicates that the degree of dispersion is low, and teachers' cognition on this issue is relatively concentrated.

Item 4: English teachers' cognition towards the dealing of the relationship between images and texts in English classroom teaching

Table 17. Descriptive Analysis of Q19-Q22 in English Teachers' Questionnaire.

\begin{tabular}{|c|c|c|c|c|c|c|c|}
\hline \multicolumn{8}{|c|}{ Q19-Q22 } \\
\hline & Mean & Std. Deviation & Very disagree & Disagree & Not sure & Agree & Strongly agree \\
\hline Q19 & 4.62 & .536 & $0(0.0 \%)$ & $0(0.0 \%)$ & $5(2.5 \%)$ & $66(33.0 \%)$ & $129 \quad(64.5 \%)$ \\
\hline Q20 & 4.48 & .665 & $0(0.0 \%)$ & $1(0.5 \%)$ & $16(8.0 \%)$ & $68(34.0 \%)$ & $(57.5 \%)$ \\
\hline Q21 & 4.68 & .511 & $0(0.0 \%)$ & $0(0.0 \%)$ & $4(2.0 \%)$ & $57(28.5 \%)$ & $(69.5 \%)$ \\
\hline Q22 & 4.57 & .631 & $0(0.0 \%)$ & $3(1.5 \%)$ & $6(3.0 \%)$ & $66(33.0 \%)$ & $(62.5 \%)$ \\
\hline
\end{tabular}

Table 17 shows the teacher's attitude towards the relationship between images and texts in classroom teaching. As for question 19, 129 people (64.5\%) agreed very much, 66 people $(33 \%)$ agreed, the mean value was 4.62 , and the standard deviation was 0.536 . For question 20,115 people $(57.5 \%)$ agreed with it very much; 68 people (34\%) agreed with it; the mean value was 4.48 ; the standard deviation was 0.665 . As for question 21, 139 people $(69.5 \%)$ agreed very much, 57 people $(28.5 \%)$ agreed, the average value was 4.68 , and the standard deviation was 0.511 . For question 22, there are 125 people who hold extraordinary agreement, accounting for $62.5 \%$; there are 66 people who hold agreement, 
accounting for $33 \%$; the average is 4.57 ; the standard deviation is 0.631 . The average value of the above four questions is close to 5 , which indicates that teachers attach importance to the processing of the relationship between pictures and texts in teaching; the standard deviation is relatively close to 0 , which indicates that the degree of dispersion is low, and teachers' processing of this problem is more concentrated.

Item 5: English teachers' attitude towards the scientific and reasonable relationship between images and texts of students preference

Table 18. Descriptive Analysis of Q11 and Q23 in English Teachers' Questionnaire.

\begin{tabular}{|c|c|c|c|c|c|c|c|}
\hline \multicolumn{8}{|c|}{ Q11 and Q23 } \\
\hline & Mean & Std. Deviation & Very disagree & Disagree & Not sure & Agree & Strongly agree \\
\hline Q11 & 4.64 & .595 & $0(0.0 \%)$ & $1(0.5 \%)$ & $9(4.5 \%)$ & $52(26.0 \%)$ & $138 \quad(69.0 \%)$ \\
\hline Q23 & 4.77 & .448 & $0(0.0 \%)$ & $0(0.0 \%)$ & $2(1.0 \%)$ & $43(21.5 \%)$ & $(77.5 \%)$ \\
\hline
\end{tabular}

Table 18 shows the attitude of students towards scientific and reasonable graphic relationship from the perspective of teachers. As for question 11, 138 people (69\%) agreed very much; 52 people (26\%) agreed; the mean value was 4.64 ; the standard deviation was 0.595 . As for question 23,155 people $(77.5 \%)$ agreed very much, and 43 people $(21.5 \%)$ agreed. The mean value was 4.77 , and the standard deviation was 0.448 . The average value of the above two questions is close to 5, which indicates that from the perspective of teachers, students' attitude towards scientific and reasonable graphic relationship is important; the standard deviation is relatively close to 0 , which indicates that the degree of dispersion is low, and students' treatment of this problem is more concentrated.

\section{Main Findings and Conclusion}

Through the above research discussion that the image presented in English textbooks as a very important teaching resources, has an irreplaceable role of text reconstruction. Both teachers and students should not ignore the role of images in English textbooks and English classroom teaching, not underestimate the role of language images in text reconstruction of English teaching.

The main findings are as follows: 1) English teachers' own knowledge foundation for text reconstruction is not enough and need enlarge the knowledge structure; 2) English teachers are not aware of the importance of images in English textbooks; 3) English teachers do not develop the habit of reading images in preparation for class; 4) English teachers are not aware of the importance of text reconstruction for students knowledge structure and cognition competence.

At same time, it can be seen some problems in the response of images using in classroom learning: 1) Students are lack of certain knowledge structure on logical relationship between language and images; 2) Students are lack of autonomous learning; 3 ) Students are lack of skills on effective methods of reading pictures and its deeper connotations.

Suggestions for English teachers are to: 1) broaden the content of different knowledge types of language images related to the text theme; 2) pay attention to the cultivation of students' perception and cognition, so as to have a better understanding of cognition level system, cultural connotation and humanistic thinking expressed in the text; 3) pay attention to improve English classroom competence of text reconstruction which can help the students understand the deeper meaning between language and images from textbooks explanation.

From the data analysis, it is found that textbook are lack of some bright images to match the text, but according to the needs of the text, through some analysis, a lot of implicit and explicit knowledge information can be obtained from the images to help students understand the text and obtain some skills or knowledge, and get some enlightenment. If teachers pay attention to guide students to analyze and understand the image in teaching when they are in the process of text reconstruction, it will play a great auxiliary role in understanding the text and improvement of language learning. Although there are still many problems in the image configuration of the selected textbooks, if teachers can carefully analyze the textbook images and flexibly use the textbook images, the classroom atmosphere can be more active and the classroom teaching efficiency can be improved.

The limitations of this study lie in the following two aspects: 1) English teachers in senior high schools are not enough to fully represent the overall situation of all English teachers in senior high schools; 2) some teachers may not answer question to follow their real teaching practice. From view of the above limitations, this study will make further improvements: 1) improve the scopes of the respondents; 2) conduct in-depth interviews with respondents to understand their attitudes deeply.

\section{Appendix}

Questionnaire Survey on Text Reconstruction of English Textbooks in Senior High School

Dear teachers!

Hello everyone! Thank you for your answers!

As a part of graduation thesis writing, we only do comprehensive statistical processing for the questionnaire data, and do not do case study. Therefore, this questionnaire is filled in anonymously, and there is no problem of private information leakage. Please feel free to fill in. There is no right or wrong answer to this questionnaire. Please answer the following questions according 
to the actual situation. Your opinions are very important to this thesis. Please don't miss any questions.

Thank you for your cooperation!

1. Personal information survey:

$\begin{array}{llr}\text { Gender__ } & \text { Age } & \text { Professional Title } \\ \text { School } & \text { Length of teaching } & \text { Textbook edition }\end{array}$

2. The following questions are the descriptions of your current English textbooks. Please answer them truthfully and tick the corresponding blanks. $(\sqrt{ })$

(Attention: $\mathrm{A}=$ Strongly agree; $\mathrm{B}=$ Agree; $\mathrm{C}=$ Not sure; $\mathrm{D}=$ Disagree; $\mathrm{E}=$ Strongly disagree)

\begin{tabular}{|c|c|c|c|c|c|c|}
\hline & Subject & A & B & C & D & $\mathbf{E}$ \\
\hline 1. & I think in the process of English classroom teaching, not only the language symbols in English textbooks are important ways & & & & & \\
\hline 2. & $\begin{array}{l}\text { In my opinion, English textbooks in senior high school expressed by words and images are conducive to our expansion of } \\
\text { teaching content or in-depth learning. }\end{array}$ & & & & & \\
\hline 3. & $\begin{array}{l}\text { In my opinion, it is necessary to construct the scientific, reasonable and complementary language image symbols in English } \\
\text { textbooks in Chinese senior high school. }\end{array}$ & & & & & \\
\hline 4. & $\begin{array}{l}\text { I think English textbooks in Chinese senior high school are conducive to enhancing students' understanding of Chinese } \\
\text { culture, forming a sense of cross-cultural communication and enhancing their international vision. }\end{array}$ & & & & & \\
\hline 5. & $\begin{array}{l}\text { In my opinion, the scientific and reasonable construction of English textbooks in Chinese senior high school is helpful for the } \\
\text { English teachers to convey the educational and cultural ideas contained in the textbooks. }\end{array}$ & & & & & \\
\hline 6. & $\begin{array}{l}\text { In my opinion, the scientific and reasonable graphic design of senior English textbooks in Chinese senior high school is } \\
\text { conducive to senior high school students' understanding and mastery of English language and cultural knowledge, and the } \\
\text { construction of English knowledge system. }\end{array}$ & & & & & \\
\hline 7. & $\begin{array}{l}\text { I think the relationship between language and image presented in English textbooks in Chinese senior high school at the } \\
\text { present stage is scientific and reasonable, and the image symbol form, layout design and color can support the text } \\
\text { reconstruction of my teaching content. }\end{array}$ & & & & & \\
\hline 8. & $\begin{array}{l}\text { In my opinion, the addition of Chinese elements in English textbooks in Chinese senior high school can better help us spread } \\
\text { and carry forward the excellent traditional Chinese culture to the world. }\end{array}$ & & & & & \\
\hline 9. & $\begin{array}{l}\text { I think the current English textbooks in Chinese senior high school should pay attention to the image content of promoting } \\
\text { Chinese traditional culture, especially the image of modern science and technology which keeps pace with the times. }\end{array}$ & & & & & \\
\hline 10. & $\begin{array}{l}\text { In my opinion, the logical relationship between language and image of Chinese traditional cultural elements and Chinese } \\
\text { history of science and technology in English textbooks in Chinese senior high school should be highlighted. }\end{array}$ & & & & & \\
\hline 11. & $\begin{array}{l}\text { In my opinion, the logical relationship between language and image reflected in the exercises of senior English textbooks in } \\
\text { Chinese senior high school is scientific and reasonable. }\end{array}$ & & & & & \\
\hline 12. & $\begin{array}{l}\text { In my opinion, in practical teaching, we should pay attention to the logical relationship between language and image in } \\
\text { English textbooks in Chinese senior high school. }\end{array}$ & & & & & \\
\hline 13. & $\begin{array}{l}\text { I think we can scientifically and accurately understand and extract the language image logical relationship and deep meaning } \\
\text { of words and images in English textbooks in Chinese senior high school. }\end{array}$ & & & & & \\
\hline 14. & $\begin{array}{l}\text { I think we should pay attention to the relationship between language and image of Chinese feelings and the education } \\
\text { orientation of students' Cultivation of Chinese feelings. }\end{array}$ & & & & & \\
\hline 15. & $\begin{array}{l}\text { I think we can supplement the logical relationship between language and image in English textbooks in Chinese senior high } \\
\text { school through other access channels. }\end{array}$ & & & & & \\
\hline 16. & $\begin{array}{l}\text { In my opinion, students prefer to learn the educational content in English textbooks in Chinese senior high school in } \\
\text { multimodal ways such as video and audio combined with language and image. }\end{array}$ & & & & & \\
\hline
\end{tabular}

\section{Acknowledgements}

We are grateful for the financial support from Social Science Foundation of Ministry of Education (No. 17YJA740032) and He'nan Social Sciences Planning Project (No. 2018BYY018).

\section{References}

[1] Ministry of Education of the People's Republic of China. (2017). English Curriculum Standards for senior high school, Beijing Normal University Press.

[2] Pu Zhu. (2008). Thinking of teaching problems, Shanghai Education Press.
[3] Yuanyuan Jin, Bin Lu. (2019). A study on the text reconstruction of senior high school English textbooks from the perspective of language image, Masterpieces Review, (33): 45-48.

[4] Hongzhen Yu. (2005). "Secondary development" of teaching materials: meaning and essence. Curriculum, teaching material and teaching method, (12): 9-13.

[5] Xia Jimei. (2008). Teaching materials, learning materials, application materials, research materials, a valuable resource for teachers' professional development, Foreign languages, (1): 6-9.

[6] Xiaotang Cheng, Xiaohui Sun. (2011). Analysis and design of English textbooks (Revised Edition), Foreign language teaching and Research Press.

[7] McDonough J, Shaw, C. (2003). Materials and Methods in ELT: a Teacher's Guide. Beijing: Peking University Press. 
[8] Alan Cunningsworth. (2002). Choosing Your Coursebook. Shanghai: Shanghai Foreign Language Education Press.

[9] McGrath, I. (2002). Materials Evaluation and Design for Language Teaching. Edinburgh: Edinburgh University Press.

[10] Tomlinson B. Materials Development Language Teaching. UK: Cambridge University Press, 1998: 2.

[11] Waters. A. (2006). Thinking and Language Learning. ELT Journal, (4): 319-326.
[12] Wittgenstein. Theory of Logical Philosophy [M]. Downloaded from Internet.

[13] Pu Zhu. (2008). An analysis of teaching topics. Shanghai: Shanghai Education Press.

[14] Weibo Mao. (2014). A study on the text reconstruction of primary school English textbooks, Ningbo University.

[15] Yan Wang. (2002). Cognitive Linguistics, Shanghai Foreign Language Education Press. 